\title{
Juxtapapillary Duodenal Diverticula and Pancreatobiliary Disease
}

\author{
Naoto Egawa Hajime Anjiki Kensuke Takuma Terumi Kamisawa \\ Tokyo Metropolitan Komagome Hospital, Tokyo, Japan
}

\section{Key Words}

Gallstone $\cdot$ Endoscopic sphincterotomy $\cdot$ Juxtapapillary duodenal diverticula $\cdot$ Pancreatobiliary disease $\cdot$ Papillary function

\begin{abstract}
Juxtapapillary duodenal diverticula (JPD) are observed in around $10-20 \%$ of patients undergoing endoscopic retrograde cholangiopancreatography (ERCP). They are acquired extraluminal outpouchings of the duodenal wall through 'locus minoris resistance' and their incidence increases with age. They have been studied mainly with regard to their association with pancreatobiliary disease. Choledocholithiasis is considered to be strongly associated with JPD, but the role of JPD in the development of cholecystolithiasis and pancreatitis is still disputable. Since JPD are located in the vicinity of the papilla of Vater, they not only cause mechanical compression of the bile duct but also induce dysfunction of the sphincter of Oddi. They are considered to lead to bile stasis and to allow reflux from the duodenum into the bile duct, which results in an ascending infection of $\beta$-glucuronidaseproducing bacteria. The ERCP procedure can be hampered by JPD, although recent papers have reported no difference in the successful cannulation rate or complications between patients with JPD and those without JPD. Disorders caused by JPD are amenable to appropriate therapy, e.g. endoscopic sphincterotomy and surgical intervention.
\end{abstract}

Copyright $\odot 2010$ S. Karger AG, Basel

\section{Introduction}

Duodenal diverticula can be either intraluminal or extraluminal. The former type is rare and congenital. They look like a sac extending distally into the duodenum, usually with an eccentric opening proximal in the sac. They are lined on both sides with duodenal mucosa and muscularis mucosa, but do not have a proper muscle layer. The latter type is predominant among duodenal diverticula. They are extraluminal outpouchings of mucosa and muscularis mucosae. Although both types of diverticula commonly arise near the papilla of Vater, juxtapapillary duodenal diverticula (JPD) usually denotes the latter, which we describe herein.

There is no consensus regarding the definition of JPD. So far, it has been defined as duodenal extraluminal diverticula located in the vicinity of the papilla of Vater, or diverticula arising within $2-3 \mathrm{~cm}$ of the papilla, or diverticula which develop within $1-2 \mathrm{~cm}$ from the papilla, and so on. In addition, some authors separate diverticula containing the papilla from those adjacent to the papilla, and only the latter are JPD. In this paper, JPD refers to diverticula not only adjacent to but also containing the papilla (intradiverticular papilla, IDP), unless otherwise indicated.

JPD per se are rarely harmful, but their association with biliary and pancreatic disease is well documented.

\section{KARGER}

Fax +4161306 1234 E-Mail karger@karger.ch www.karger.com
(C) 2010 S. Karger AG, Basel

0253-4886/10/0272-0105\$26.00/0

Accessible online at:

www.karger.com/dsu
Naoto Egawa, MD

Tokyo Metropolitan Komagome Hospital

3-18-22 Honkomagome, Bunkyo-ku

Tokyo 113-8677 (Japan)

Tel. +81 33823 2101, Fax +81 33824 1552, E-Mail naoto@ cick.jp 
Fig. 1. JPD located on the oral side of the papilla.

Fig. 2. JPD is shown adjacent to the lower bile duct. Eight years ago, this patient underwent cholecystectomy. Since then, he had two episodes of acute cholangitis due to recurrent biliary duct stones.

1

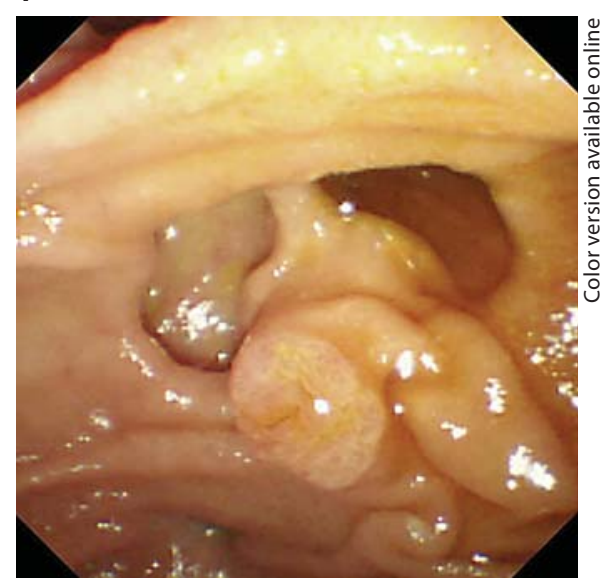

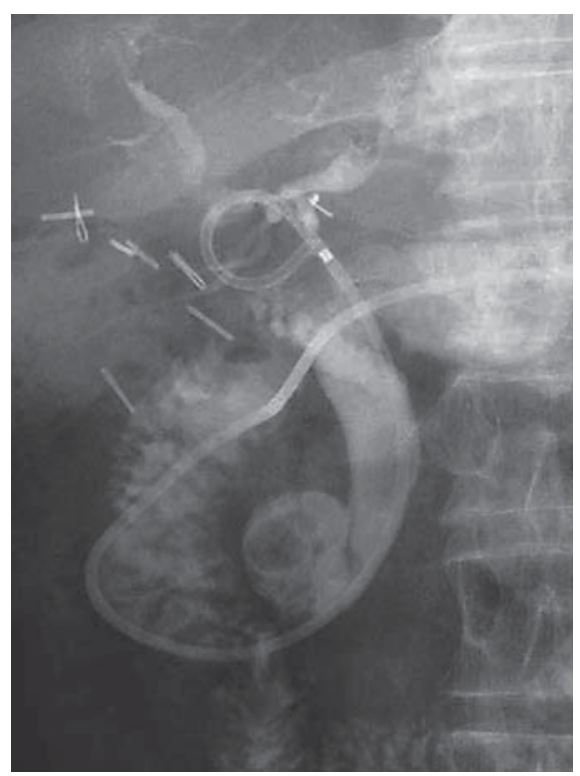

\section{Incidence of JPD}

Various incidence rates have been reported, and it is difficult to tell the exact incidence in a general population. The variation is due to the different study methods used and the different ages of the subjects investigated. A recent barium study showed a prevalence of $6 \%$ [1], and in studies employing endoscopic retrograde cholangiopancreatography (ERCP), it varied between 4.1 and $31.7 \%$, with most around $10-20 \%$ [2-9]. On the other hand, a rate of $19.4 \%$ has been reported at autopsy [10]. JPD prevalence increases with age [10]. There seems to be no gender predilection. The vast majority of JPD are located on the oral side of the major papilla [9] (fig. 1).

\section{Pathogenesis of JPD}

JPD are thought to be acquired as described elsewhere in the gastrointestinal tract. The development of JPD is related to anatomical characteristics of the periampullary region and embryological features of the pancreas, both of which are closely associated with the so-called 'locus minoris resistance'. Suda et al. [11] clearly verified that JPD nearly always penetrate the pancreas along the embryological fusion line of the ventral and dorsal pancreas, which is a weak spot that offers the easiest pathway for a diverticulum. In addition, they demonstrated that JPD also occur at weak spots in the duodenal wall, such as the perivascular connective tissue sheath pathway and at the entrance of the common bile duct and pancreas duct.

In aged subjects, a weakened wall and increased luminal pressure may facilitate outpouching of the duodenal mucosa through the vulnerable spot.

\section{JPD and Biliary Tract Disease}

Multiple studies have demonstrated a possible association between JPD and gallstone disease. However, in some of these studies, patients with gallstones accompanied by JPD were not precisely matched in terms of sex and age to suitable controls. Since the incidence of gallstones is higher in females than in males, and since the incidence of both JPD and gallstones increases with age, it is important to adjust for gender and age when describing the relationship.

In this setting, Osnes et al. [2] reported that the incidence of biliary calculi was significantly higher in patients with JPD than in those without JPD, and the difference was significant for all age groups $>40$ years. In this study, biliary calculi indicated choledocholithiasis and cholecystolithiasis, collectively. When these two sites where stones exist are studied separately, most papers have accepted the fact that choledocholithiasis was primarily correlated with JPD [3-6] (fig. 2).

Regarding cholecystolithiasis, controversy still exists regarding the causal relationship between JPD and stone formation. In one series of 227 autopsied cases, cholecystolithiasis and choledocholithiasis were found at a ratio 
of 4:1 both in cases with JPD and in cases without JPD, although the incidence of gallstones in cases with JPD was significantly higher than that in cases without JPD [10]. On the other hand, Hagège et al. [5] concluded that the prevalence of JPD was increased in patients with common bile duct stones but not in those with gallbladder stones alone, based on findings in 483 subjects undergoing endoscopic retrograde cholangiography. Some other reports also support this result $[6,8,9]$. We reported a series of 1,386 patients with satisfactory ERCP. Among them, after adjusting for age and gender, 180 patients with JPD and 369 patients without JPD were compared with regard to the incidence of choledocholithiasis and cholecystolithiasis. Our results were consistent with those of Hagège et al. [12]. However, we also noted that JPD were statistically larger in patients with cholecystolithiasis than in those without (mean 21.0 vs. $15.5 \mathrm{~mm}$ ), and JPD $\geq 20 \mathrm{~mm}$ seem to predispose the patient to gallbladder stones compared to smaller JPD (the incidence of cholecystolithiasis 73.3 vs. $49.6 \%$ ), while a comparable relationship was not seen for choledocholithiasis [12].

Løtveit et al. [13] reported that pigment stones were formed in the gallbladder at a significantly higher incidence in patients with JPD than in those without, even in the absence of common bile duct stones. Kimura et al. [10] also indicated that JPD may be involved in the pathogenesis of gallbladder bilirubinate stones. Pigment and bilirubinate stones are thought to be derived from bile contaminated by bacteria and are closely related to dysfunction of the sphincter of Oddi under JPD, as mentioned below. This means that JPD may also play a role in the formation of gallbladder stones.

Without choledocholithiasis, JPD can cause acute cholangitis. This is manifested as a symptom of Lemmel's syndrome. In a series of 337 patients with both JPD and cholangitis, Chiang et al. [14] compared 39 patients diagnosed as having Lemmel's syndrome with the other 298 patients. They found that the former were significantly older and had significantly larger diverticula (mean 3.9 vs. $1.9 \mathrm{~cm}$, respectively). In addition, the incidence of IDP was higher in patients with Lemmel's syndrome than in those without (30.8 vs. $8.7 \%$ ).

\section{JPD and Pancreatic Disease}

It has been a matter of dispute whether or not pancreatitis is induced by JPD per se. As described above, JPD predispose the patient to common bile duct stones, which can cause pancreatitis.

Juxtapapillary Duodenal Diverticula
Leivonen et al. [6] reviewed ERCP of 86 patients with JPD, and reported that patients with JPD had idiopathic pancreatitis twice as often as the control patients (11.4 vs. $5.6 \%$, respectively), but this difference was not statistically significant. In a series of 350 pairs of patients with and without JPD reported by Zoepf et al. [8], there were no significant differences in the frequencies of acute and chronic pancreatitis.

On the other hand, several studies lend support to the notion that JPD may play a role in the development of pancreatitis. In a comparison of 42 patients with JPD and 428 patients without JPD, Leinkram et al. [1] found that patients with JPD but without gallstones had a significantly higher frequency of relapsing or chronic pancreatitis. Uomo et al. [7] concluded that JPD should be included in a list of possible etiological factors, based on a study of 439 patients with ERCP, which found a significantly higher incidence of idiopathic acute pancreatitis in patients with JPD than in those without. More recently, Naranjo-Chavez et al. [15] stressed that only ampullary diverticula within which the common bile duct and pancreatic duct end should be an etiologic factor for chronic pancreatitis.

\section{JPD and Non-Pancreatobiliary Complications}

The complications reported are diverticulitis, bleeding, bezoars, perforation, cyclic vomiting and so on, although these are all very rare.

\section{Special Reference to the Relationship between IDP and Pancreatobiliary Disease}

IDP is expected to be strongly affected by JPD. Matsumoto et al. [16] reported that abnormalities in the intrahepatic bile duct (gallstone and/or dilatation) were observed more frequently in patients with IDP than in patients with diverticulum on the oral side of the papilla. They also showed that abnormal findings in the distal portion of the common bile duct, such as flexion, compression, or tapering, were seen more frequently in cases of IDP [16]. Our study showed that gallbladder stones tended to be formed more often in patients with IDP than in those with papilla other than IDP, when the JPD was $\geq 20 \mathrm{~mm}$ in size [unpubl. data]. Furthermore, as mentioned above, Naranjo-Chavez et al. [15] stated that diverticula containing the papilla played an important role in the etiology of chronic pancreatitis and Chiang et al. [14]

Dig Surg 2010;27:105-109 
revealed a higher incidence of Lemmel's syndrome in patients with IDP. Furthermore, according to a study by Takaaki et al. [17] with endoscopic biliary manometry, abnormal motor activity of the sphincter of Oddi related to JPD is more frequent in subjects with IDP.

However, few studies have focused on the relationship between IDP and pancreatobiliary diseases.

\section{Pathophysiology of Pancreatobiliary Disease Associated with JPD}

Bile duct dilatation is significantly more common in patients with JPD than in those without JPD [4]. This is partly due to mechanical compression, which induces deformity of the lower part of the common bile duct by a diverticulum per se. There are some anecdotal reports of cases with biliary obstruction by a JPD filled with food residue.

The sphincter of Oddi regulates biliary and pancreatic flow into the duodenum and also prevents the reflux of duodenal juice into the duct system as well as pancreatobiliary reflux. Since JPD are located close to the orifice of the papilla of Vater, JPD have been considered to play a role in sphincter of Oddi dysfunction.

Several studies have confirmed this hypothesis through the use of biliary manometry. Løtveit et al. [18] studied patients with cholecystectomy and a normal common bile duct. By comparing patients with and without JPD, they found that the muscular tone, contractile activity, and total rhythmic variation of the sphincter of Oddi were significantly less in patients with JPD than in controls. Kubota et al. [19] also showed that in cholecystolithiasis patients the incidence of papillary dysfunction was significantly greater in those with JPD than in those without JPD. Miyazaki et al. [20] used intraoperative cholangiography to show that JPD could cause a mechanical obstruction of the terminal biliary ductal system in the presence of a duodenal pressure load, and confirmed the results of Løtveit et al.

Bacteriobilia is another factor for pancreatobiliary disease associated with JPD. In a series of 72 patients with common bile duct stones treated with endoscopic papillotomy, Skar et al. [21] demonstrated an increased occurrence of bacteria producing $\beta$-glucuronidase and an increased activity of bacterial $\beta$-glucuronidase in the bile in patients with duodenal diverticula. They considered that bacterial glucuronidase was an etiologic factor in pigment gallstone in such patients, since $\beta$-glucuronidase deconjugates bilirubinate glucuronides in bile, resulting in the formation of gallstones. This coincides with the fact that common bile duct stones formed in patients with JPD are mainly pigment stones. They also revealed that patients with diverticula have significantly greater bacterial overgrowth in the duodenum compared to those without diverticula. The bacteria they isolated from the duodenum (e.g. Escherichia coli, Streptococcus faecalis, and Klebsiella sp.) were almost the same as those from the bile [22].

In conclusion, the dysfunction of the sphincter of Oddi which leads to bile stasis and allows reflux from the duodenum into the duct system and ascending infection is considered to be critical for pancreatobiliary disease.

\section{JPD and ERCP}

JPD can be an impediment to ERCP procedures. Some authors have described the technical difficulty of cannulation and a higher rate of bleeding after endoscopic sphincterotomy $[8,14]$. The level of difficulty seems to depend on the location of the papilla, i.e. whether it is inside or outside of diverticulum, with the former being more critical. To overcome this problem, a two-devices-in-onechannel method has been developed [23]. In the original description of this method, a biopsy forceps and a catheter are inserted together into the working channel of a duodenoscope and the former is used to pinch the duodenal mucosa distal to the papilla and pull the papilla out of the diverticulum. As a modification of this method, pancreatic-duct guide-wire placement is also useful. However, more recent papers have shown that the successful cannulation rate, and morbidity and mortality rates after ERCP are almost the same between patients with and without JPD [24]. This might be attributable to the recent development of new devices and/or new manipulations such as a sphincterotome-based technique or wire-guided cannulation, which is now prevalent and is taking the place of conventional cannulation in Western countries.

\section{Treatment}

Asymptomatic diverticula are not indicated for treatment. Emergent events such as bleeding and perforation are major indications for radiological or surgical intervention. Choledocholithiasis should be treated in a conventional way, either endoscopically or surgically. For acalculous cholangitis as a manifestation of Lemmel's syndrome, endoscopic therapeutics including endoscopic sphincterotomy have been reported to be effective [14]. 


\section{References}

$\nabla_{1}$ Leinkram C, Roberts-Thomson IC, Kune GA: Juxtapapillary duodenal diverticula. Med J Aust 1980;1:209-210.

$\checkmark 2$ Osnes M, Løtveit T, Larsen S, Aune S: Duodenal diverticula and their relationship to age, sex, and biliary calculi. Scand J Gastroenterol 1981;16:103-107.

$\checkmark 3$ Løtveit T, Osnes M, Larsen S: Recurrent biliary calculi: duodenal diverticula as a predisposing factor. Ann Surg 1982;196:30-32.

$\checkmark 4$ Shemesh E, Friedman E, Czerniak A, Bat L: The association of biliary and pancreatic anomalies with periampullary duodenal diverticula. Arch Surg 1987;122:1055-1057.

$\checkmark 5$ Hagège H, Berson A, Pelletier G, Fritsch J, Choury A, Liguory C, Etienne JP: Association of juxtapapillary diverticula with choledocholithiasis but not with cholecystolithiasis. Endoscopy 1992;24:248-251.

6 Leivonen MK, Halttunen JA, Kivilaakso EO: Duodenal diverticulum at endoscopic retrograde cholangiopancreatography, analysis of 123 patients. Hepatogastroenterology 1996; 43:961-966.

7 Uomo G, Manes G, Ragozzino A, Cavallera A, Rabitti PG: Periampullary extraluminal duodenal diverticula and acute pancreatitis: an underestimated etiological association. Am J Gastroenterol 1996;91:1186-1188.

$>8$ Zoepf T, Zoepf DS, Arnold JC, Benz C, Riemann JF: The relationship between juxtapapillary duodenal diverticula and disorders of the biliopancreatic system: analysis of 350 patients. Gastrointest Endosc 2001;54:5661.

$\checkmark 9$ Kim MH, Myung SJ, Seo DW, Lee SK, Kim YS, Lee MH, Yoo BM, Min MI: Association of periampullary diverticula with primary choledocholithiasis but not with secondary choledocholithiasis. Endoscopy 1998;30: 601-604.
10 Kimura W, Nagai H, Kuroda A, Muto T: No significant correlation between histologic changes of the papilla of Vater and juxtapapillary diverticulum. Scand J Gastroenterol 1992;27:951-956.

11 Suda K, Mizuguchi K, Matsumoto M: A histopathological study on the etiology of duodenal diverticulum related to the fusion of the pancreatic anlage. Am J Gastroenterol 1983;78:335-338.

12 Egawa N, Kamisawa T, Tu Y, Sakaki N, Tsuruta $\mathrm{K}$, Okamoto A: The role of juxtapapillary duodenal diverticulum in the formation of gallbladder stones. Hepatogastroenterology 1998;45:917-920.

13 Løtveit T, Foss OP, Osnes M: Billiary pigment and cholesterol calculi in patients with and without juxtapapillary duodenal diverticula. Scand J Gastroenterol 1981;16:241244.

14 Chiang TH, Lee YC, Chiu HM, Huang SP, Lin JT, Wang HP: Endoscopic therapeutics for patients with cholangitis caused by the juxtapapillary duodenal diverticulum. Hepatogastroenterology 2006;53:501-505.

15 Naranjo-Chavez J, Schwarz M, Leder G, Beger HG: Ampullary but not periampullary duodenal diverticula are an etiologic factor for chronic pancreatitis. Dig Surg 2000;17: 358-363.

16 Matsumoto J, Shibue T, Hashimoto S: Relationship between perivaterian diverticulum and biliary tract disease. Gastroenterol Jpn 1985;20:577-581.

$>17$ Takaaki J, Kodama T, Akaki H, Fukui Y, Furuya S, Morita $\mathrm{M}$, Kashima K: Relationship between juxtapapillary duodenal diverticulum and biliopancreatic disease. Evaluation by endoscopic biliary manometry (in Japanese). Nippon Shokakibyo Gakkai Zasshi 1992;89:1270-1278.
18 Løtveit T, Osnes M, Aune S, Larsen S: Studies of the choledocho-duodenal sphincter in patients with and without juxta-papillary duodenal diverticula. Scand J Gastroenterol 1980;15:875-880

19 Kubota K, Itho T, Shibayama K, Shimada K, Nomura Y, Idezuki Y: Papillary function of patients with juxtapapillary duodenal diverticulum. Consideration of pathogenesis of common bile duct stones. Scand J Gastroenterol 1989;24:140-144.

20 Miyazaki S, Sakamoto T, Miyata M, Yamasaki Y, Yamasaki H, Kuwata K: Function of the sphincter of Oddi in patients with juxtapapillary duodenal diverticula: evaluation by intraoperative biliary manometry under a duodenal pressure load. World J Surg 1995; 19:307-312.

21 Skar V, Skar AG, Bratlie J, Osnes M: Betaglucuronidase activity in the bile of gallstone patients both with and without duodenal diverticula. Scand J Gastroenterol 1989;24: 205-212.

22 Skar V, Skar AG, Osnes M: The duodenal bacterial flora in the region of papilla of Vater in patients with and without duodenal diverticula. Scand J Gastroenterol 1989;24: 649-656.

$>23$ Fujita N, Noda Y, Kobayashi G, Kimura K, Yago A: ERCP for intradiverticular papilla: two-devices-in-one-channel method. Gastrointest Endosc 1998;48:517-520.

24 Tham TC, Kelly M: Association of periampullary duodenal diverticula with bile duct stones and with technical success of endoscopic retrograde cholangiopancreatography. Endoscopy 2004;36:1050-1053. 